\title{
APARATO EDUCACIONAL PROMOVIDO PELO ESTADO EM PROL DA EMPREGABILIDADE 1
}

\author{
Cleide Francisca de Souza Tano² \\ Adriana Cristina Omena dos Santos ${ }^{3}$ \\ Carlos Lucena 4 \\ Robson Luiz de França ${ }^{5}$
}

\section{RESUMO}

Este artigo visa discutir o aparato educacional promovido pelo Estado em prol da empregabilidade e redução das desigualdades sociais, a partir dos anos 2000, em atendimento às demandas do mercado/capital, objetivando melhor compreender as nuanças dessas medidas. É parte integrante da tese de doutorado da autora, defendida em dezembro de 2019, com orientações dos coautores. A metodologia adotada foi a pesquisa bibliográfica e a pesquisa documental, numa perspectiva histórico crítica. O trabalho apresenta considerações sobre o contexto e a historicidade da política de formação do trabalhador, apresentando dados sobre a educação profissional e suas perspectivas, perpassando pela expansão da rede de educação profissional e tecnológica e tratando mais especificamente do Instituto Federal do Triângulo Mineiro - IFTM e da relação de seus cursos com o setor agroindustrial de Uberlândia, além de apresentar nuanças da escolarização, remuneração e emprego formal em Uberlândia. Dentre os autores que fundamentam a pesquisa destacam-se Hobsbawm (2015); Batista (2015); Cury (2014); Saviani (2005); Lucena (2014); Fagiani e Previtali (2014); Tano (2016) e Ciavatta (2010). Este trabalho auxilia a melhor compreender as políticas elaboradas pelo Estado, que trazem no seu bojo o argumento de incentivo à empregabilidade e à redução das desigualdades sociais, mas que, na realidade, não poderá mudar o que está posto no tocante ao desemprego, pois no nível do desenvolvimento histórico do sistema capitalista o desemprego é uma característica marcante. Esperamos que este trabalho contribua com reflexões tanto sobre o emprego e sobre o aparato educacional promovido pelo Estado quanto sobre a efetividade das políticas governamentais.

Palavras-chave: Educação profissional. Empregabilidade. Setor produtivo agroindustrial de Uberlândia.

\footnotetext{
1 Este texto é parte integrante da pesquisa de doutorado, defendida pela autora em dezembro de 2019 com orientações dos coautores.

2 Doutora em Educação, Universidade Federal de Uberlândia. Orcid iD: http://orcid.org/0000-0001-6160-114X.E-mail: cleidetano@yahoo.com.br

3 Doutora em Ciências da Comunicação (ECA/USP). Orcid iD: https://orcid.org/0000-00028863-6219. E-mail: adriomena@gmail.com

${ }_{4}^{4}$ Doutor em Educação, Universidade Federal de Uberlândia. Orcid iD: https://orcid.org/00000003-0546-5053. E-mail: Iucenabonsais@gmail.com
}

${ }^{5}$ Doutor em Educação, Universidade Federal de Uberlândia. Orcid iD: https://orcid.org/00000001-7966-961X. E-mail: rlfranca@ufu.br 


\section{EDUCATIONAL APPARATUS PROMOTED BY THE STATE FOR EMPLOYABILITY}

\section{ABSTRACT}

This article aims to discuss the educational apparatus promoted by the State in favor of employability and reduction of social inequalities, starting in the 2000s, in response to market / capital demands, aiming to better understand the nuances of these measures. It is an integral part of the author's doctoral thesis, defended in December 2019, with guidance from the co-authors. The methodology adopted was bibliographic research and documentary research, in a critical historical perspective. The paper presents considerations on the context and historicity of the worker training policy, presenting data on professional education and its perspectives, covering the expansion of the professional and technological education network and dealing more specifically with the Instituto Federal do Triângulo Mineiro - IFTM and the relationship of its courses with the agro-industry sector of Uberlândia, besides presenting nuances of schooling, remuneration and formal employment in Uberlândia. Among the authors that support the research, we highlight Hobsbawm (2015); Batista (2015); Cury (2014); Saviani (2005); Lucena (2014); Fagiani and Previtali (2014); Tano (2016) and Ciavatta (2010). This article helps to better understand the policies elaborated by the State, which bring within them the argument of encouraging employability and the reduction of social inequalities, but which, in reality, cannot change what is set regarding unemployment, because in the historical development of the capitalist system unemployment is a remarkable feature. We hope that this work will contribute to reflections both on employment and on the educational apparatus promoted by the State and on the effectiveness of government policies.

Keywords: Professional education. Employability. Uberlândia agro-industrial productive sector.

\section{APARATO EDUCATIVO PROMOCIONADO POR EL ESTADO PARA LA EMPLEABILIDAD}

\section{RESUMEN}

Este artículo tiene como objetivo discutir el aparato educativo impulsado por el Estado a favor de la empleabilidad y la reducción de las desigualdades sociales, a partir de la década del 2000, en respuesta a las demandas del mercado / capital, con el objetivo de comprender mejor los matices de estas medidas. Es parte integral de la tesis doctoral del autor, defendida en diciembre de 2019, con la orientación de los coautores. La metodología adoptada fue la investigación bibliográfica y la investigación documental, en una perspectiva histórica crítica. El trabajo presenta consideraciones sobre el contexto y la historicidad de la política de formación del trabajador, presentando datos sobre la formación profesional y sus perspectivas, cubriendo la expansión de la red de educación profesional y tecnológica y abordando más específicamente el Instituto Federal do Triângulo Mineiro - IFTM y la relación de sus cursos el sector agroindustrial de Uberlândia, además de presentar matices de escolaridad, remuneración y empleo formal en Uberlândia. Entre los autores que apoyan la investigación, destacamos Hobsbawm (2015); Batista (2015); 
Cury (2014); Saviani (2005); Lucena (2014); Fagiani y Previtali (2014); Tano (2016) y Ciavatta (2010). Este trabajo ayuda a comprender mejor las políticas elaboradas por el Estado, que traen consigo el argumento de incentivar la empleabilidad y la reducción de las desigualdades sociales, pero que, en realidad, no pueden cambiar lo planteado en materia de desempleo, porque en el el nivel del desarrollo histórico del sistema capitalista, el desempleo es una característica notable. Esperamos que este trabajo contribuya a reflexionar tanto sobre el empleo como sobre el aparato educativo impulsado por el Estado y sobre la efectividad de las políticas gubernamentales.

Palabras clave: Educación profesional. Empleabilidad. Sector productivo agroindustrial de Uberlândia.

\section{INTRODUÇÃO}

Este trabalho visa discutir o aparato educacional promovido pelo Estado em prol da empregabilidade e redução das desigualdades sociais, a partir dos anos 2000, em atendimento às demandas do mercado/capital, objetivando melhor compreender as nuanças dessas medidas.

Para tanto, apresenta, discute e analisa as políticas de formação do trabalhador da região Geográfica Intermediária de Uberlândia, mais especificamente a instituição do Instituto Federal do Triângulo Mineiro - IFTM, com cursos na sua grande maioria capazes de fornecer força de trabalho altamente qualificada.

Informamos que este artigo é parte integrante da tese de doutorado defendida pela autora em dezembro de 2019, com orientações dos coautores, em que esta parte da hipótese que apesar de as agroindústrias de alimentos serem um dos ramos mais interiorizados do setor industrial e da região ter sido privilegiada pela política de expansão da educação profissional e tecnológica, os trabalhadores da região Geográfica Intermediária de Uberlândia não conseguem se inserir, de forma efetiva, no mercado de trabalho, porque o setor produtivo prefere contratar pessoas com formação superior às reais exigências das atividades pelo mesmo valor de mercado, devido à grande oferta de trabalhadores altamente qualificados, que estão desempregados.

A autora destaca que a inserção de forma efetiva no mercado de trabalho, considerada na pesquisa, é aquela em que há um contrato formal, 
em que o trabalhador exerce funções que requerem o grau de escolaridade compatível com a sua formação.

A metodologia adotada foi a pesquisa bibliográfica e a documental em fontes primárias e secundárias, numa perspectiva histórico crítica. A discussão é importante no universo acadêmico, uma vez que poderá subsidiar futuras contribuições tanto para o emprego, quanto para os cursos ofertados pelo IFTM, e também contribui para reflexões acerca da efetividade das políticas governamentais.

Por conta disto, consideramos importante apresentarmos o contexto e a historicidade da Política de Formação do Trabalhador, enfatizando as implantadas a partir dos anos 2000, em especial o Programa de Expansão da Rede Federal de Educação Profissional.

\section{CONTEXTO E HISTORICIDADE DAS POLÍTICAS DE FORMAÇÃO DO TRABALHADOR}

A compreensão do objeto de estudo exige que não se perca de vista a totalidade social na qual ele está inserido. Ao longo dos tempos, várias mudanças se consolidaram nas estruturas produtivas mundialmente, promovendo alterações significativas nas relações entre trabalho e educação.

Hobsbawm (2015), ao discutir as mudanças do século XX, elucida que as transformações nas formas de trabalho e o aumento do desemprego retratam as transformações do capitalismo. Saviani (2005) afirma que a transformação do capitalismo afetou as relações de trabalho e a educação no século XX e se mantém presente no princípio do século XXI. Segundo esse autor, na primeira revolução industrial, o processo produtivo e a organização do trabalho sob a égide do Taylorismo-Fordismo apresentaram, como principal característica, a economia de escala e a produção para o consumo em massa.

Percebe-se, na explicação desse autor, que nesse processo o contingente de trabalhadores era muito expressivo, fato que facilitava a organização sindical e contribuía para manter certo grau de compromisso 
entre o Estado, empresas e sindicato dos trabalhadores, assegurando um relativo equilíbrio social.

Na trajetória do capitalismo, os estudos apresentados por Cury (2014) e Saviani (2005) mostram que as transformações nos processos produtivos passaram a demandar também dispêndios para com a educação do trabalhador, porém esta motivação ocorreu por conta de fatores econômicos e não sociais ou culturais. A educação passou a ser concebida como dotada de valor econômico à luz da "Teoria do Capital Humano", desenvolvida por Theodore William Schultz, economista estadunidense.

Seguindo a mesma linha de pensamento, Saviani $(2005$, p. 23) explica que Schultz verificou que a qualificação influenciava no desempenho da economia, e ainda que o aumento no grau de escolaridade mantinha relação direta com o aumento na renda dos indivíduos. Nesse sentido, a educação, no período de 1950 a 1970, seguiu os pressupostos do taylorismofordismo, através da "pedagogia tecnicista".

No Brasil, o surgimento das indústrias, a concentração de habitantes cada vez maior nas cidades e as transformações no mundo do trabalho ocorreram concomitantemente com graves problemas sociais, tais como desemprego e falta de moradia, de saúde e de educação. Batista (2015) explica que, na primeira metade do século XX, o aumento da população nas cidades, tanto pelo processo de abolição de escravatura e êxodo rural, quanto pelo processo imigratório, levou a burguesia a balancear as possibilidades de investir no trabalhador vindo do meio rural.

Tano (2016), apresenta um resgate histórico da formação profissional brasileira desde 1909, discutindo sobre: a criação das Escolas de Aprendizes e Artífices, no território nacional, destinadas às crianças e adolescentes, com o intuito de livrar da criminalidade e do ócio; Reforma Capanema; e sobre as Constituições brasileiras, bem como sobre leis e decretos que tratam sobre a formação dos indivíduos.

Percebemos, na legislação e nos estudos apresentados pela autora, que a história da educação profissional brasileira é marcada por um processo contraditório, em que a dualidade é uma característica marcante 
e que o Estado ora vincula e ora desvincula a educação profissional ao ensino médio. Essas mudanças nas superestruturas acompanham as mudanças nas estruturas produtivas mundialmente, conforme nos ensina Marx (2013).

Nas palavras de Saviani (2005), as diferenças entre as revoluções podem ser observadas. Segundo o autor:

Diferentemente da primeira revolução industrial, que operou a transferência das funções manuais para as máquinas, essa nova revolução transfere para as máquinas as próprias operações intelectuais, razão pela qual esta época é também chamada de "era das máquinas inteligentes". Nesse processo, a capacidade do trabalho humano inegavelmente atinge proporções ilimitadas. [...] 0 avanço tecnológico foi utilizado para alterar o padrão produtivo, introduzindo a acumulação flexível a qual substituiu o taylorismofordismo pelo toyotismo, com o que se deslocaram os mecanismos de controle no interior das próprias empresas, secundarizando 0 papel dos sindicatos e do Estado (SAVIANI, 2005, p. 21-22).

Reflexões sobre as considerações apresentadas por Saviani (2005) permitem inferir que os impactos dessa nova revolução foram mais abrangentes. Seus estudos mostram que, além das transformações nos processos produtivos, alteram-se também as concepções de emprego e de educação. A concepção de emprego, que antes era visto como uma solução para a crise, nesse novo processo converte-se em um dos elementos do processo de controle da crise, uma vez que a maximização da exploração da força de trabalho mantém relação direta com a crescente manutenção do controle do desemprego.

Com a segunda revolução industrial alterou-se o padrão produtivo, conforme citado anteriormente, mas também provocou-se mudanças significativas nos processos educacionais. Dentre as consequências dessa revolução, destacam-se: o aumento do desemprego; a busca pela flexibilização nas relações de trabalho; e a diversificação da organização escolar e do trabalho pedagógico. Porém, Saviani $(2005$, p. 23) enfatiza que: "em ambos períodos, prevalece a busca pela produtividade guiada pelo princípio da racionalidade, que se traduz no empenho em se atingir $o$ 
máximo de resultados com o mínimo de dispêndio", ou seja, no contexto da reestruturação produtiva a meta primária é o lucro.

Nos estudos apresentados por Saviani (2005), especificamente sobre as transformações que ocorreram no campo da educação desde a primeira revolução industrial, percebemos que essas mudanças tiveram como pressuposto a formação dos indivíduos voltada sempre para o mercado de trabalho, além do acolhimento social para as classes menos favorecidas. Os pressupostos da educação integrada, de preparar o cidadão para além do capital, conforme a perspectiva de autores como Mészáros (2008), Saviani (2008) e Ciavatta e Reis (2010), não se fazem presentes, até então.

Todavia, o estudo da historicidade das políticas de formação do trabalhador mostra que a educação profissional, voltada para a preparação dos indivíduos para uma profissão, com o passar dos tempos ganhou maior ênfase. Apesar de existir desde a colonização brasileira, foi com a Lei de Diretrizes e Bases da Educação Nacional (LDB) n 9.394/1996 que o Estado concedeu uma importância maior para esse tipo de formação escolar.

Na trajetória das políticas educacionais brasileiras, a partir dos anos 2000, a educação começa a passar por outro processo de transformação; temos, então, a inclusão da concepção de educação integrada nos documentos oficiais do Brasil que tratam sobre a educação.

A pesquisa de Tano (2016) mostra avanços sem precedentes na educação brasileira a partir das políticas implantadas nos anos 2000. Esses avanços vão além do número de instituições e de matrículas e perpassam pelo aumento do número de acesso ao ensino superior por parte de jovens, que não teriam esse acesso com políticas nos moldes dos programas anteriores. Em decorrência disto é importante discorrer acerca da educação profissional a partir dos anos 2000 e suas perspectivas para melhor compreender o objeto de estudo.

\section{Educação profissional a partir dos anos 2000 e suas perspectivas}


Diversos autores discutem sobre a formação profissional no início do século XXI, dentre eles destacamos Frigotto, Ciavatta e Ramos (2005), que apresentam um debate sobre a gênese do Decreto $n^{\circ}$ 5.154/2004 e a revogação do Decreto 2.208/1997. Esses autores consideram que esse debate ocorre em um contexto controverso da democracia restrita, sinalizando para incongruências de forças sociais e do próprio governo sobre um tema que eles consideram não poder ser negligenciado, pois se trata de um direito social que precisa ser cumprido.

Segundo Frigotto, Ciavatta e Ramos (2005, p. 3), enquanto a Lei $n^{\circ}$ 9.394/96 "sinalizava a formação profissional integrada à formação geral nos seus múltiplos aspectos humanísticos e científico-tecnológicos", o Decreto 2.208/1997 representava um retrocesso, pois veio não apenas "proibir a pretendida formação integrada, mas regulamentar formas fragmentadas e aligeiradas de educação profissional em função das alegadas necessidades do mercado".

As considerações dos autores citados permitem compreender que 0 Decreto 5.154/2004 altera principalmente questões relacionadas com a organização curricular da educação profissional desenvolvida articulada com o ensino médio.

Percebemos também no estudo do Decreto 5.154/2004 que esse documento não prevê limite para aproveitamento da carga horária do ensino médio para o ensino profissional técnico. Nas reflexões sobre esses documentos e sobre as políticas oficiais de formação profissional, percebemos que muitos programas governamentais foram influenciados a partir do Decreto 5.154/2004, bem como foram estabelecidos diversos documentos, como resoluções e atos normativos da Educação Profissional e Tecnológica. Todavia esse Decreto foi conciliador, não impôs a formação integrada.

Dentre esses documentos aprovados destacam-se: a Resolução $n^{\circ} 1$, de 3 de fevereiro de 2005, do Conselho Nacional de Educação (CNE) e da Câmara de Educação Básica (CEB), que atualiza as Diretrizes Curriculares Nacionais definidas pelo Conselho Nacional de Educação para o Ensino 
Médio e para a Educação Profissional Técnica de nível médio às disposições do Decreto n 5.154/2004; a Resolução CNE/CEB n³ 3, de 9 de julho de 2008, que institui a implantação de Catálogo Nacional de Cursos Técnicos de Nível Médio; e a Resolução CNE/CEB no 6 de 20 de setembro de 2012, que estabelece as Diretrizes Curriculares Nacionais para a Educação Profissional Técnica de Nível Médio.

Posteriormente, em 2008, a Lei $n^{0} 11.741$ altera dispositivos da Lei $n^{\circ}$ 9.394, de 20 de dezembro de 1996, uma vez que veio redimensionar, institucionalizar e integrar as ações da educação profissional técnica de nível médio, da educação de jovens e adultos e da educação profissional tecnológica. Dentre as formas de educação profissional e tecnológica, destaca-se a Educação Profissional Técnica de Nível Médio que pode acontecer de três formas: integrada, em que há uma matrícula única; concomitante e subsequente.

O Decreto $n^{\circ} 7.690 / 2012$ aprova a criação da Secretaria de Educação Profissional e Tecnológica, e então têm várias ações e programas implantados. Dentre os programas implantados, merecem destaque: Programa de Expansão da Rede Federal de Educação Profissional Científica e Tecnológica; Programa Brasil Profissionalizado; Rede e-Tec Brasil; Programa Mulheres Mil; Programa Nacional de Integração da Educação Profissional com a Educação Básica na Modalidade de Educação de Jovens e Adultos; e Programa de Formação Profissional em Serviço dos Funcionários da Educação.

Dentre esses programas, a proposta de educação integrada para o ensino médio representa um grande avanço na educação Brasileira. Contribui para esse avanço a Resolução CNE/CEB $n^{\circ} 2$, de 30 de janeiro de 2012, que vem com uma proposta de considerar o trabalho como um princípio educativo.

Ao analisar estes documentos, percebemos que eles possuem um discurso político que representa um avanço em direção a uma educação integrada em relação ao que estava posto, porém é fundamental a adoção de uma postura crítica, pois diversos autores ensinam que não é porque o 
cidadão brasileiro tem um direito garantido pela legislação que significa dizer que este direito seja efetivado na prática. A realidade de muitas escolas de ensino médio no Brasil ainda é precária, assim como as condições de trabalho dos docentes.

Entretanto, não se pode deixar de observar que, se com uma legislação tendente a uma educação integral, em uma perspectiva mais emancipadora, ainda existem diversos problemas relacionados com a qualidade da educação, devemos então indagar como será a educação brasileira com retrocessos visíveis no aparato legal, como aponta a Medida Provisória $n^{\circ} 746$, de 22 de setembro de 2016, convertida na Lei $n^{\circ} 13.415$, de 16 de fevereiro de 2017.

O aprofundamento do estudo sobre essa Lei é muito importante, sendo que é um tema sugerido para outras pesquisas pelo seu caráter contraditório e de imposição, uma vez que se trata de uma legislação com alterações significativas no campo da educação, mas cuja aprovação foi feita sem a participação e envolvimento de todos os profissionais da educação, ou seja, não ocorreu em uma perspectiva democrática.

Cabe também questionarmos sobre o financiamento da educação. Se o Estado, com as medidas atuais de cortes no orçamento da educação, terá como financiar a educação no tempo integral, em todas as escolas, ou ainda, terá condições de ampliar as estruturas das escolas, ampliando o quadro de servidores, uma vez que muitas instituições de ensino possuem condições não satisfatórias para atender a demanda nos moldes da legislação anterior.

Além disto, reflexões sobre o artigo $n^{\circ}$ 6, da Lei $n^{\circ} 13.415$, de 16 de fevereiro de 2017, que vem modificar o artigo $n^{\circ} 61$ da Lei $n^{\circ} 9.394 / 96$, que dispõe sobre quais profissionais poderão ser considerados profissionais da educação escolar básica, nos permitem considerar que, com aprovação e implantação desta Lei há uma tendência a desvalorização ainda maior do docente, uma vez que permite aos profissionais com notório saber ministrar conteúdos de áreas afins à sua formação ou experiência profissional (BRASIL, 2017). 
Diante das más perspectivas para a educação e do contexto da aprovação da Lei n 13.415/2017, marcado por crises política e econômica, em que o desemprego e a crise da democracia aparecem como fenômenos emblemáticos, consideramos importante enfatizar a relevância dos programas implantados nos anos 2000.

Em 2008, a educação brasileira teve um grande avanço com o Programa de Expansão da Rede Federal de Educação Profissional Científica e Tecnológica, através da Lei $n^{\circ} 11.741 / 2008$, mencionada anteriormente, que institui a Educação Profissional e Técnica de Nível Médio, como modalidade da educação básica, alterando dispositivos da Lei de Diretrizes e Bases da Educação.

Segundo essa Lei, a educação profissional técnica de nível médio será desenvolvida das seguintes formas: articulada com o ensino médio e subsequente, em cursos destinados a quem já tenha concluído o ensino médio. A forma articulada será desenvolvida integrada ou concomitante.

Essa expansão significou um avanço sem precedentes no campo da educação profissional e tecnológica, tanto por questões relacionadas aos investimentos em infraestrutura, em valorização do docente, quanto em fornecer condições para que o estudante possa ter acesso ao ensino superior, dentre outras formas de apoio ao estudante.

Em decorrência disto, a discussão do próximo tópico recairá sobre o Programa de Expansão da Rede Federal de Educação Profissional, mais especificamente sobre a criação IFTM, uma vez que buscaremos identificar a relação dos seus cursos com o setor agroindustrial da região em estudo, em especial com a cidade de Uberlândia.

\section{PROGRAMA DE EXPANSÃO DA REDE FEDERAL DE EDUCAÇÃO PROFISSIONAL CIENTÍFICA E TECNOLÓGICA}

É emblemático para a compreensão do Programa de Expansão da Rede Federal de Educação Profissional discutir o que estava posto no campo da educação profissional e do trabalho até os anos de 1990. Porém, 
ressaltamos que o Programa de Expansão da Rede Federal de Educação Profissional Científica e Tecnológica não significou uma ruptura com o que estava posto, mas representa um avanço sem precedente, conforme mencionado.

Os estudos de França e Scocuglia (2011), Soares (1998), Lucena et al. (2014), dentre outros, revelam que as políticas relacionadas com a formação do trabalhador apresentam características de política assistencialista e compensatória, muito diferente de política voltada para a formação integral do cidadão.

Destacam a importância de elucidar que "há um discurso recorrente e utilizado como forma de individualizar o problema da não empregabilidade, - qual acusa o sistema educacional pela má qualidade da formação escolar implementada". Esses autores observam no período em análise "a configuração de uma proposta de formação para o trabalho que se propõe a estar totalmente separada da educação formal e escolarizada" (FRANÇA; SCOCUGLIA, 2011, p. 27).

Soares (1998, p. 197-199) também explica que "as políticas têm revelado muito mais um caráter de inserção social, com muito ainda para melhorar". Dentre os pontos analisados e apontados pela autora como carentes de algo novo, sem vícios, destacam-se os processos de formação docente, o uso de metodologias adequadas e a participação da sociedade civil.

O histórico da educação profissional brasileira mostra, entretanto, que importantes mudanças ocorreram no início do século XXI. Dentre essas mudanças merecem destaque a transformação e integração dos Centros de Ensino e Escolas Técnicas em Institutos Federais e a materialização da expansão da Rede Federal de Educação Profissional, Científica e Tecnológica.

Dois aparatos legais foram importantes nesse processo. Um deles é a Lei $n^{\circ} 11.741 / 2008$, que alterou a LDB n 9.394/1996, integrando a educação profissional de nível médio à Educação de Jovens e Adultos à educação profissional e tecnológica. Além disso, implantou a modalidade de formação 
inicial e continuada, estendendo a formação profissional aos níveis de graduação e pós-graduação.

O outro aparato relevante é a Lei $n^{\circ} 11.892 / 2008$, que instituiu a Rede Federal de Educação Profissional, Científica e Tecnológica. Foram criados 38 Institutos Federais de Educação, Ciência e Tecnologia. Posteriormente, em 2012, a Lei n 12.677, que equiparou o Colégio Pedro II aos Institutos Federais.

Destacamos que, para compreender a expansão da Rede de Educação Profissional, Científica e Tecnológica, não podemos deixar de analisar os interesses que estavam em disputa na implantação dessa política. Não é por acaso que o empresariado atuou efetivamente na formulação de muitos dos documentos que nortearam a educação no governo Lula, assim como fazia em outros governos.

No período de 2003 a 2015 foram criados vários campis dos Institutos Federais em diversos municípios brasileiros. Até 2002 havia apenas 120 municípios brasileiros atendidos pela educação profissional e, com a expansão dos Campi, em 2014 eram 512 municípios atendidos por essa política, representando uma expansão de aproximadamente $426 \%$ no número de municípios atendidos.

Balsadi (2001) e Locatel (2012) explicam que essa expansão acompanhou a trajetória do capital. Como exemplos em Minas Gerais, São Paulo e Goiás, houve um grande número de indústrias que se deslocaram das cidades para o campo. As teorias que estudam a trajetória do capitalismo ensinam que esse movimento é uma característica típica do neoliberalismo.

Os documentos que tratam sobre a política de expansão da educação profissional, científica e tecnológica, bem como as informações sobre os cursos ofertados pelos institutos em seus sites, mostram também que muitos dos cursos implantados são voltados para setores estratégicos da economia nacional. Portanto, o apoio ao setor agrícola e agroindustrial não é uma promessa recente, do atual governo; é histórico o apoio do Estado aos interesses desses setores. 
O estudo dos programas e projetos, bem como dos documentos que norteiam essa política, desvela o interesse do setor produtivo nas instalações destes institutos próximos às suas unidades produtivas. Inclusive, Saviani (2009), ao analisar o PDE, ressalta que, ao implantar suas políticas, o Estado priorizou a interlocução com o setor produtivo em detrimento aos ideais dos profissionais da educação.

Os estudos apresentados mostram que a educação profissional e tecnológica ocupa, ao longo do tempo, lugar importante na agenda dos governantes brasileiros, embora ora avance, ora retroceda. Em decorrência disso, é necessário conhecer a relação da educação profissional com o setor produtivo, de modo especial na cidade foco da pesquisa.

\section{IFTM e a relação de seus cursos com o setor agroindustrial da região de Uberlândia}

Minas Gerais é o estado com maior número de institutos federais. São 5 institutos mais o CEFET-MG, o Instituto Federal Norte de Minas Gerais; o Instituto Federal Sudeste de Minas Gerais; o Instituto Federal de Minas Gerais; o Instituto Federal Sul de Minas Gerais e o Instituto Federal Triângulo Mineiro (IFTM).

O IFTM foi criado como modelo de reorganização das instituições federais de educação profissional e tecnológica. Sua criação ocorreu em consonância com a Lei n ${ }^{\circ} 11.892$, de 29 de dezembro de 2008. Foi constituído mediante a integração do Centro Federal de Educação Tecnológica de Uberaba, CEFET-Uberaba e suas Unidades de Ensino Descentralizadas (UNED) de Ituiutaba e de Paracatu e da Escola Agrotécnica Federal de Uberlândia (EAF-Uberlândia).

Os números da pesquisa de Tano (2016) mostram que, até 2014, foram 392 campi dos Institutos Federais a mais em relação a 2002, beneficiando a população de um número de municípios ainda maior. No caso específico do IFTM, os dados retratam o aparato montado pelo Estado, a partir de 2010, no tocante à educação básica na modalidade da Educação Profissional 
Tecnológica de Nível Médio e também nos níveis mais elevados da educação, oferecidos nos Institutos Federais.

Destacamos também que, além dos cursos Técnicos Concomitantes ao Ensino Médio, na modalidade presencial, foram implantados cursos: Ensino Técnico Concomitante ao Ensino Médio, na modalidade à Distância; Técnico Integrado ao Ensino Médio, na modalidade presencial; e Inglês, Espanhol e Francês nos níveis básico, intermediário e avançado, vinculados à Central de Idiomas.

Os dados sobre os cursos do IFTM, coletados em seu site, mostram que foram criados 13 cursos de Ensino Técnico Concomitante ao Ensino Médio, na modalidade presencial em 10 Campi/polos, sendo implantadas 22 turmas, no mínimo, uma vez que não identificamos o número de turmas de um mesmo curso que foram implantadas em cada polo. No tocante aos Cursos de Ensino Técnico Concomitante ao Ensino Médio, à distância, foram implantados 05 cursos no polo Uberaba - Parque Tecnológico.

Quanto ao Ensino Técnico Integrado ao Ensino Médio, na modalidade presencial, foram implantados 12 cursos em 08 Campi/polos, tendo sido implantados 24 turmas, no mínimo, dessa modalidade. Consideramos que essa modalidade em conjunto com outras políticas e medidas afirmativas, vem apresentado resultados expressivos no que se refere ao processo de formação dos educandos, permitindo-os, inclusive acessar ao ensino superior nos cursos mais disputados da educação, representando, assim, tema importante para ser discutido em outras pesquisas.

Pesquisa feita no site do IFTM, em 2019, mostra também que em relação aos níveis mais elevados da educação, foram implantados 03 cursos de licenciaturas à distância no polo Uberaba - Parque Tecnológico e 19 cursos de graduação presencial em 08 Campi/polos, oferecendo a região, no mínimo, 26 turmas, uma vez que houve casos de cursos que foram implantados em mais de um polo.

No tocante aos níveis mais elevados da educação, foram implantados 10 cursos de Pós-Graduação Lato Sensu Especialização Presencial em 04 
Campi/Polos e 04 cursos de Pós-Graduação Stricto Sensu e Mestrado Presencial nos Campi Uberaba e Uberaba Parque Tecnológico.

Quanto ao número de polos e campi, foram implantados 11 nas cidades de Campina Verde, Ibiá, Ituiutaba, Paracatu, João Pinheiro, Patos de Minas, Patrocínio, Uberaba e Uberlândia, uma vez que estas duas últimas contam com dois campi cada uma, conforme dados do Portal do IFTM, acesso em maio de 2019.

A partir de reflexões sobre o panorama da expansão da Rede de Educação Profissional Científica e Tecnológica, de modo especial, dos campi/polos do IFTM e da relação dos cursos implantados com o setor produtivo local, percebemos que a sociedade e de modo especial o setor produtivo da cidade de Uberlândia e região foram privilegiados com diversos cursos que visam à formação da força de trabalho nos mais elevados níveis da educação.

De modo especial, o setor das indústrias de transformação, em que estão inseridas as agroindústrias de alimentos, foi privilegiado com cursos de formações específicas para seus ramos de negócios; dentre eles destacamse os cursos de nível médio: Agroindústria, Agropecuária; Automação Industrial; Alimentos; e Química, além de cursos com correlação direta a todos os empreendimentos como Administração, Contabilidade, Informática, Segurança do Trabalho, Meio Ambiente, Inglês, entre outros.

Além desses cursos, o setor citado também foi bastante privilegiado com o aparato do Estado para a formação de força de trabalho altamente especializada, com cursos de Pós-Graduação em nível de especialização como: Controle de Qualidade em Processos Alimentícios; Geoprocessamento; Higiene e Segurança Alimentar; Ciências Ambientais; além de cursos com correlação a todos os ramos de negócios como: Gestão de Negócios; Análise e Desenvolvimento de Sistemas Aplicados à Gestão Empresarial e outros. Em nível de Mestrado, esse setor foi privilegiado com cursos como: Mestrado Profissional em Ciências e Tecnologia de Alimentos; Mestrado Profissional em Produção Vegetal e outros. 
Os méritos dessa política perpassam o número de cursos e o número de municípios atingidos. O quadro dos profissionais, em especial, o corpo docente dos Institutos Federais, também merece destaque. No caso do IFTM, grande número de professores possui titulação em nível de Mestrado e Doutorado, fato que contribui para a pesquisa, para o processo formativo ofertado nas instituições tanto de ensino médio quanto de ensino superior, bem como proporciona aos alunos melhores condições de serem bem classificados nas avaliações externas, além de proporcionar grandes chances de acesso ao ensino superior, uma vez que o papel do docente é primordial no processo formativo.

Diversos são os benefícios que essa política de expansão da educação profissional e tecnológica trouxe para a sociedade. Dentre esses benefícios destacamos os incentivos ao ensino, pesquisa e extensão e a ampliação e construção dos institutos, sendo que $o$ investimento em infraestrutura foi expressivo.

Outra pesquisa feita no portfólio do IFTM permite compreender que houve planejamento para a construção dos campi/polos do IFTM e que esses foram construídos em áreas capazes de proporcionar uma formação integral dos alunos, com campos para experimentos, diversos laboratórios, salas de aulas, auditórios, quadras esportivas, academias, escritórios, salas de apoio pedagógico e demais espaços para o atendimento ao aluno e adequados à aprendizagem.

Revela também que houve grande investimento em infraestrutura e também em apoio ao aluno e aos processos de ensino aprendizagem de modo geral. A política de expansão da rede de educação profissional e tecnológica permite perceber que essa não é uma política de governo, é uma política de Estado, que perpassa o período de gestão dos governantes e carece de ser incentivada e aprimorada.

Além do investimento em estruturas físicas, outra contribuição importante que os institutos estão proporcionando para a sociedade está relacionada com os relatórios de pesquisas e produção acadêmica desenvolvida por seus pesquisadores e alunos. 
Todo esse aparato contribui com o setor produtivo local, fornecendo força de trabalho altamente qualificada e conhecimento científico e tecnológico para o desenvolvimento de diversos ramos de atividades. A cidade de Uberlândia, conforme mencionamos, destaca-se dentre as cidades mais importantes de Minas Gerais, com significativa participação no PIB regional e nacional e é uma das cidades privilegiadas por contar com dois polos dos Institutos Federais, além de localizar-se próxima a outros 03 polos importantes do IFTM, os dois IFTM de Uberaba e também o de Ituiutaba.

Todos esses polos possuem cursos voltados para os principais setores da economia regional e Uberlandense. Em decorrência disso, no tópico seguinte, discutiremos a relação entre Educação e empregabilidade, com foco nas nuanças da escolarização, remuneração e emprego formal em Uberlândia.

\section{Relação educação e empregabilidade: nuanças da escolarização, remuneração e emprego formal em Uberlândia}

Os estudos apresentados permitem considerar que, para uma sociedade ser mais justa e menos desigual, é fundamental que os processos formativos sejam colocados em uma perspectiva integral, humanizadora e que o interesse particular da classe hegemônica não sobressaia ao coletivo.

Com o intuito de melhor compreender a realidade em estudos, citamos os dados do Centro de Pesquisa Econômico-Sociais - CEPES da Universidade Federal de Uberlândia - UFU, que apresentam a dinâmica socioeconômica da então mesorregião do Triângulo Mineiro e Alto Paranaíba (TMAP), desenvolvendo uma análise sobre o emprego formal, vínculos e estabelecimentos além de discutir a situação do emprego formal em Uberlândia no período de 2010 a 2016.

Sobre o estoque de emprego formal, nos anos 2000-2015, os dados mostram que, no ano 2000, o Estoque de Emprego Formal, no Brasil, Minas Gerais e TMAP eram, respectivamente: 26.228.639; 2.803.454 e 302.489. Em 
2015, computavam respectivamente: 48.060.807; 4.821.116 e 604.773 . Representando assim, de 2000 para 2015, uma variação positiva de aproximadamente: $83 \% ; 72 \%$ e 100\%, nas respectivas cidades. Sobre o emprego formal em Uberlândia, Oliveira (2018) apresenta a evolução conforme o estoque de emprego formal em Uberlândia no período de 2010 a 2016.

Aparentemente os dados demonstrados no relatório do CEPES, por Oliveira (2018) apresentam um cenário favorável até 2014, com queda no número de empregos em Uberlândia a partir de 2015. Entretanto, os pesquisadores responsáveis pelos estudos econômicos do CEPES (2019) ressaltam que os dados mencionados devem ser interpretados com a devida cautela, uma vez que não estão levando em conta que aqui não está sendo considerada a evolução da População Economicamente Ativa (PEA) no período analisado.

A noção da dimensão do tamanho do desemprego e das desigualdades sociais começa a ser desvelada ao correlacionar os dados do número de emprego com outras variáveis, como população economicamente ativa, escolarização, remuneração e outras, quando se almeja compreender suas relações.

Ferreira e Oliveira (2017) apresentam a distribuição do estoque de emprego formal por faixa salarial, no Brasil, Minas Gerais, Triângulo Mineiro e Alto Paranaíba e Uberlândia em 2010 e 2016. Já, os dados apresentados por Oliveira (2019) na cidade de Uberlândia, em 2016, dos 209.438 vínculos ativos, havia 42.092 pessoas com empregos formais e escolarização em nível superior completo, porém apenas 18.607 habitantes recebiam acima de 5 salários, sem considerar os não classificados.

Os números apresentados por Ferreira e Oliveira (2017) revelam a desigualdade salarial brasileira. Em 2016, no caso específico de Uberlândia, aproximadamente $57,1 \%$ das pessoas com vínculos ativos só recebiam até 2 salários mínimos e apenas aproximadamente $8,88 \%$ da população recebiam acima de 5 salários mínimos, ou seja, apenas 18.607 habitantes. 
Esses dados revelam outro dilema quando correlacionados com as variáveis escolarização da população empregada e os dados da ocupação nos grandes setores da economia apresentados pelo CEPES/IE/UFU (2019), uma vez que os números mostram que grande parte da população é altamente escolarizada, porém recebe menos de 5 salários mínimos.

Os números mostram também que a evolução do número da população empregada em Uberlândia de 2010 para 2016 subiu aproximadamente $14,21 \%$, enquanto que, no TMAP, subiu aproximadamente 12,01\%; em Minas Gerais diminuiu aproximadamente 0,39\% e no Brasil aumentou aproximadamente $4,52 \%$.

Esses dados também, em uma análise apenas quantitativa, podem retratar um cenário promissor. Porém, Oliveira (2018) alerta que é necessário ter cautela ao analisar os dados sobre a dinâmica de Uberlândia. A pesquisadora, ao correlacionar o estoque de emprego formal com grau de escolaridade ensino superior completo, em Uberlândia, em 2016, com as dez principais ocupações da Classificação Brasileira das Ocupações (CBO 2002), em Uberlândia e no mesmo ano, afirma que as informações revelam outra realidade.

Esses dados analisados isoladamente não retratam a essência do que está posto. A análise apresentada pela autora citada, no relatório CEPES/IERI/UFU afirma que:

\begin{abstract}
Verifica-se que algumas das ocupações que foram tomadas pelos trabalhadores com grau de escolaridade em questão, a priori, não requerem ensino superior completo, como é o caso de: auxiliar de escritório, assistente administrativo, professor de nível médio na educação infantil, e supervisor administrativo. Ainda assim, essas quatro ocupações responderam juntas por cerca de $14 \%$ do estoque de emprego formal de trabalhadores com ensino superior no município (OLIVEIRA, 2018, p. 25-26).
\end{abstract}

As constatações da autora revelam que há trabalhadores com curso superior exercendo atividades que, a priori, não requerem alta qualificação/titulação. O olhar crítico sobre o rol de dados apresentados permite perceber que as considerações de Oliveira (2018) nos remetem às 
considerações de Fagiani e Previtali (2014) sobre a nova configuração da classe trabalhadora do século XXI, uma vez que esses autores apontam que há um acréscimo em números no quantitativo de emprego, porém em condições de trabalho nada favoráveis ao trabalhador.

\section{CONSIDERAÇÕES FINAIS}

Conforme já apresentado este trabalho visa discutir 0 aparato educacional promovido pelo Estado em prol da empregabilidade e redução das desigualdades sociais, a partir dos anos 2000, em atendimento às demandas do mercado/capital, objetivando melhor compreender as nuanças dessas medidas.

No desenvolvimento deste trabalho apresentamos considerações sobre o contexto e a historicidade da política de formação do trabalhador, apresentando dados sobre a educação profissional e suas perspectivas, perpassando pela expansão da rede de educação profissional e tecnológica e tratando mais especificamente do IFTM e da relação de seus cursos com o setor agroindustrial de Uberlândia e apresentando nuanças da escolarização, remuneração e emprego formal em Uberlândia.

Consideramos que esta discussão permite compreender que são históricos os avanços e retrocessos da educação profissional no Brasil. No caso específico da expansão da rede de educação profissional no Brasil, consideramos que esta representa um avanço sem precedente, pois significa um aparato educacional capaz de formar força de trabalho altamente qualificada e ainda o ensino médio integrado ao ensino técnico, aliado a medidas afirmativas tem fornecido aos alunos dos Institutos Federais a oportunidade de ter acesso ao ensino superior.

No caso específico do setor agroindustrial de Uberlândia, os dados permitem inferir que o setor foi beneficiado por grande número de cursos ofertados pelo IFTM.

Os dados da pesquisa permitem também conhecer o número de empregos formais, bem como a escolarização das pessoas empregadas e 
faixa salarial. A análise destes dados permite considerar que houve um aumento da inserção das pessoas no mercado de trabalho, porém não de forma efetiva, em que há contrato formal e que o trabalhador exerça funções que requeiram grau de escolaridade compatível com a sua formação.

Os dados apresentados permitem confirmar a hipótese levantada e em uma análise na perspectiva crítica, os dados sobre o emprego correlacionando com outras variáveis, como população economicamente ativa, escolarização e remuneração, conforme citado, desvela outra realidade, em que o desemprego é fenômeno marcante e que as condições para o trabalhador não são favoráveis.

Consideramos que o trabalho contribui tanto com o setor produtivo, seja ele grandes ou pequenos arranjos produtivos locais, à medida que retrata o potencial do aparato educacional que o Estado disponibiliza tanto para o setor, quanto para a sociedade de modo geral, uma vez que auxilia a melhor compreender as políticas elaboradas pelo Estado, que trazem no seu bojo o argumento de incentivo à empregabilidade e à redução das desigualdades sociais, mas que, na realidade, não poderá mudar o que está posto no tocante ao desemprego, pois no nível do desenvolvimento histórico do sistema capitalista o desemprego é uma característica marcante.

Esperamos que este trabalho contribua com reflexões tanto sobre o emprego e sobre o aparato educacional promovido pelo Estado quanto sobre a efetividade das políticas governamentais.

\section{REFERÊNCIAS}

BALSADI, $O$. $\vee$. Mudanças no meio rural e desafios para o desenvolvimento sustentável. São Paulo, 2001. DOI: http://dx.doi.org/10.1590/S010288392001000100017. Disponível em: http://www.scielo.br/scielo.php?script=sci_arttext\&pid=s010288392001000100017. Acesso em: 14 dez. 2017.

BATISTA, E. L. Trabalho e educação profissional nas décadas de 1930 e 1940 no Brasil: análise do pensamento e das ações da burguesia industrial a partir do IDORT. Campinas: Autores Associados, 2015. DOI: 
https://doi.org/10.20396/rho.v13i51.8640287. Disponível em: https://periodicos.sbu.unicamp.br/ojs/index.php/histedbr/article/view/864028 7. Acesso em: 08 de março de 2018.

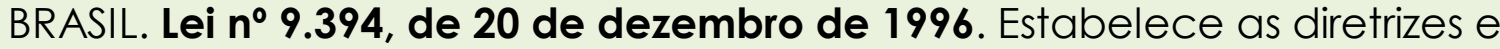
bases da educação nacional. Brasília: Ministério da Educação,1996.

Disponível em: http://www.planalto.gov.br/ccivil_03/leis/19394.htm. Acesso em: 18 jan. 2019.

BRASIL. Decreto $n^{\circ}$ 2.208, de 17 de abril de 1997. Regulamenta o $\S 2^{\circ}$ do art. 36 e os arts. 39 a 42 da Lei n 9.394, de 20 de dezembro de 1996, que estabelece as diretrizes e bases da educação nacional. 1997b. Disponível em: http://www.planalto.gov.br/ccivil_03/decreto/D2208.htm. Acesso em: 18 jan. 2019.

BRASIL. Decreto $n^{\circ}$ 5.154, de 23 de julho de 2004. Regulamenta o $\S 2^{\circ}$ do art. 36 e os arts. 39 a 41 da Lei $n^{\circ}$ 9.394, de 20 de dezembro de 1996, que estabelece as diretrizes e bases da educação nacional, e dá outras providências. Brasília: Ministério da Educação, 2004. Disponível em: http://www.planalto.gov.br/ccivil_03/_ato20042006/2004/decreto/d5154.htm. Acesso em: 18 jan. 2019.

BRASIL. Lei $n^{\circ}$ 11.741, de 16 de julho de 2008. Altera dispositivos da Lei $n^{\circ} 9.394$, de 20 de dezembro de 1996, que estabelece as diretrizes e bases da educação nacional, para redimensionar, institucionalizar e integrar as ações da educação profissional técnica de nível médio, da educação de jovens e adultos e da educação profissional e tecnológica. 2008a. Disponível em: http://www.planalto.gov.br/ccivil_03/_ato2007-2010/2008/lei/l1 1741.htm. Acesso em: 10 mar. 2019.

BRASIL. Lei $n^{\circ}$ 11.892, de 29 de dezembro de 2008. Institui a Rede Federal de Educação Profissional, Científica e Tecnológica, cria os Institutos Federais de Educação, Ciência e Tecnologia, e dá outras providências. 2008b. Disponível em: http://www.planalto.gov.br/ccivil_03/_Ato20072010/2008/Lei/L1 1892.htm. Acesso em: 10 mar. 2019.

BRASIL. Decreto 7.690, de 02 de março de 2012. Aprova a Estrutura Regimental e o Quadro Demonstrativo dos Cargos em Comissão e das Funções Gratificadas do Ministério da Educação. 2012a. Disponível em: http://www.planalto.gov.br/ccivil_03/_Ato20112014/2012/Decreto/D7690.htm. Acesso em: 10 dez. 2018.

BRASIL. Lei $n^{\circ} \mathbf{1 2 . 6 7 7}$, de 25 de junho de 2012. Dispõe sobre a criação de cargos efetivos, cargos de direção e funções gratificadas no âmbito do Ministério da Educação, destinados às instituições federais de ensino; altera as Leis $n^{\circ} 8.168$, de 16 de janeiro de 1991, 11.892 , de 29 de dezembro de 2008, e 11.526, de 4 de outubro de 2007; revoga as Leis $n^{\circ} 5.490$, de 3 de setembro 
de 1968, e 5.758, de 3 de dezembro de 1971, e os Decretos-Leis $n^{\circ} 245$, de 28 de fevereiro de 1967, 419, de 10 de janeiro de 1969, e 530, de 15 de abril de 1969; e dá outras providências. 2012b. Disponível em:

http://www.planalto.gov.br/ccivil_03/_Ato2011-2014/2012/Lei/L12677.htm. Acesso em: 10 mar. 2019.

BRASIL. Medida Provisória ${ }^{\circ}$ 746, de 22 de setembro de 2016. Institui a Política de Fomento à Implementação de Escolas de Ensino Médio em Tempo Integral, altera a Lei $n^{\circ}$ 9.394, de 20 de dezembro de 1996, que estabelece as diretrizes e bases da educação nacional, e a Lei no 11.494 de 20 de junho 2007, que regulamenta o Fundo de Manutenção e Desenvolvimento da Educação Básica e de Valorização dos Profissionais da Educação, e dá outras providências. 2016. Disponível em:

https://www2.camara.leg.br/legin/fed/medpro/2016/medidaprovisoria-74622-setembro-2016-783654-publicacaooriginal-151 123-pe.html. Acesso em: 10 dez. 2018.

BRASIL. Lei $n^{\circ}$ 13.415, de 16 de fevereiro de 2017. 2017. Altera as Leis $n^{\circ} 9.394$, de 20 de dezembro de 1996, que estabelece as diretrizes e bases da educação nacional, e 11.494, de 20 de junho 2007, que regulamenta o Fundo de Manutenção e Desenvolvimento da Educação Básica e de Valorização dos Profissionais da Educação, a Consolidação das Leis do Trabalho - CLT, aprovada pelo Decreto-Lei n 5.452, de $1^{\circ}$ de maio de 1943, e o Decreto-Lei $n^{\circ} 236$, de 28 de fevereiro de 1967; revoga a Lei $n^{\circ} 11.161$, de 5 de agosto de 2005; e institui a Política de Fomento à Implementação de Escolas de Ensino Médio em Tempo Integral. 2017. Disponível em: http://www.planalto.gov.br/ccivil_03/_Ato2015-2018/2017/Lei/L13415.htm. Acesso em: 02 fev. 2019.

\section{CEPES/IE/UFU. Número de Empregados em $31 / 12$ segundo Grau de} Escolaridade e Grandes Setores IBGE - 1994 a 2016. 2016. Disponível em: http://www.ie.ufu.br/sites/ie.ufu.br/files/Anexos/Bookpage/CEPES_ODIN_Merc _Trab_Formal_Udia_Tabela06_1994a2016.pdf. Acesso em: 12 de março de 2019.

CIAVATTA, M.; REIS, R. R. A pesquisa histórica em trabalho e educação. Brasília: Liber Livro, 2010. ISBN: 978-85-7963-020-0.

CURY, C. R. J. Octogésimo ano da "Reconstrução Educacional no Brasil: manifesto dos pioneiros da educação nova, do povo e do governo". In: LIMA, A. B.; CARVALHO, C. H.; PREVITALI, F. S. (Orgs.). O Manifesto dos Pioneiros da Educação: leituras sobre seus 80 anos. Jundiaí: Paco, 2014. ISBN: 978-85-81 48-627-7.

FAGIANI, C. C.; PREVITALI, F. S. A nova configuração da classe trabalhadora no século XXI: qualificação e precarização. Revista Ciência do Trabalho. n. 3. Dez. 2014. ISSN 2319-0574. 
FERREIRA, E. W.; OLIVEIRA, A. S. Análise do Emprego Formal - Vínculos e Estabelecimentos - na Mesorregião do Triângulo Mineiro e Alto Paranaíba TMAP. In: CORRÊA, V. P. (Org.). Dinâmica Socioeconômica da Mesorregião do Triângulo Mineiro e Alto Parnaíba. Uberlândia: CEPES/IE/UFU, V. 4, maio 2017. 133p. Disponível em:

http://www.ie.ufu.br/sites/ie.ufu.br/files/Anexos/Bookpage/PE16_Dinamica_So cioEcon_TMAP_V_4_Emprego.pdf. Acesso em: 12 mar. 2019.

FRANÇA, R. L.; SCOCUGLIA, A. C. C. O discurso e a educação profissional de nível técnico e tecnológico. In: SCOCUGLIA, A. C. C. et al. (Org.). O controle do trabalho no contexto da reestruturação produtiva do capital. 1 ed. Curitiba: CRV, 2011 . ISBN 978-85-8042-039-5.

FRIGOTTO, G.; CIAVATTA, M.; RAMOS, M. A gênese do Decreto n. 5.154/2004: um debate no contexto controverso da democracia restrita. Revista Trabalho Necessário. 2005. Ano 3, número 3. ISSN: 1808-799X. DOI: https://doi.org/10.22409/tn.3i3.p4578. Disponível em: http://periodicos.uff.br/trabalhonecessario/article/view/4578/0. Acesso em: 09 de março de 2018.

HOBSBAWM, E. Era dos Extremos: o breve século XX - 1914 - 1991. Tradução de Marcos Santarrita. Revisão técnica de Maria Célia Paoli. São Paulo: Companhia das Letras, $2^{a}$ Ed. 53 $3^{a}$ reimp. e atual. 2015. ISBN 978-85-7164-468-7.

IBGE. Divisão regional do Brasil em regiōes geográficas imediatas e regiões geográficas intermediárias: 2017//BGE. Coordenação de Geografia. Rio de Janeiro: IBGE, 2017. ISBN 978-85-240-4418-2. Disponível em:

https://www.ibge.gov.br/apps/regioes_geograficas/. Acesso em: 03 de jan. de 2018.

IBGE - Instituto Brasileiro de Geografia e Estatística. Produto interno bruto dos municípios: 2010-2013. IBGE, Coordenação Contas Nacionais. Rio de Janeiro: IBGE, 2015 (Contas Nacionais, ISSN 1415-9813; n. 49). ISBN 978-85-240-4372-7.

IFTM. Conhecendo o Instituto Federal de Educação, Ciência e Tecnologia do Triângulo Mineiro. Portfólio IFTM. 2016. Disponível em:

http://www.iftm.edu.br/publicacoes/. Acesso em: 09 fev. 2019.

IFTM. Cursos Oferecidos. Disponível em: http://www.iftm.edu.br/cursos/. Acesso em: 03 maio 2019.

IFTM. Institucional. Disponível em: https://iftm.edu.br/acesso-ainformacao/institucional/. Acesso em: 03 de maio de 2019.

LOCATEL, C. Tecnificação dos Territórios Rurais no Brasil: Políticas Públicas e Pobreza. Scripta Nova - Revista Electrónica de Geografia Y Ciências Sociales. Barcelona: Universidad de Barcelona. 1 de nov. de 2012, vol. XVI, n 418, v. 
66. ISSN: 1138-9788. Não Paginado. Disponível em:

http://www.ub.edu/geocrit/sn/sn-418/sn-418-66.htm. Acesso em: 20 de maio de 2018.

LUCENA, C. et al. Mundialização e Trabalho: um debate sobre a formação dos trabalhadores no Brasil. In: LOMBARDI, J. C.; LUCENA, C.; PREVITALI, F. S. (Org.). Mundialização do Trabalho, transição histórica e reformismo educacional. São Paulo, Campinas: Librum, 2014. ISBN 978-85-65608-13-8.

MARX. K. O Capital: crítica da economia política - Livro I: o processo de produção do capital. Tradução de Rubens Enderle. São Paulo: Boitempo, 2013. ISBN 978-85-7559-320-2.

MEC/CNE/CEB. Resolução $\mathbf{n}^{\circ} \mathbf{1}$, de $\mathbf{3}$ de fevereiro de $\mathbf{2 0 0 5}$. Atualiza as Diretrizes Curriculares Nacionais definidas pelo Conselho Nacional de Educação para o Ensino Médio e para a Educação Profissional Técnica de nível médio às disposições do Decreto n 5.154/2004. Disponível em: http://portal.mec.gov.br/cne/arquivos/pdf/rceb001_05.pdf. Acesso em: 10 dez. 2018.

MEC/CNE/CEB. Resolução $\mathbf{n}^{\circ}$ 03, de 09 de julho de 2008. Dispõe sobre a instituição e implantação do Catálogo Nacional de Cursos Técnicos de Nível Médio. Acesso em: 10 dez. 2018. Disponível em:

http://portal.mec.gov.br/index.php?option=com_docman\&view=download \&alias=10940-rceb003-08\&ltemid=30192. Acesso em: 10 dez. 2018.

MEC/CNE/CEB. Resolução nº 6, de 20 de setembro de 2012. 2012a. Define Diretrizes Curriculares Nacionais para a Educação Profissional Técnica de Nível Médio. Disponível em:

http://portal.mec.gov.br/index.php?option=com_docman\&view=download \&alias=1 1663-rceb006-12-pdf\&category_slug=setembro-2012pdf\&ltemid=30192. Acesso em: 10 dez. 2018.

MEC/CNE/CEB. Resolução 2, de 30 de janeiro de 2012. 2012b. Define Diretrizes Curriculares Nacionais para o Ensino Médio. Disponível em: http://portal.mec.gov.br/index.php?option=com_docman\&view=download \&alias=9864-rceb002-12\&ltemid=30192. Acesso em: 10 dez. 2018.

MÉSZÁROS, I. A educação para além do capital. São Paulo: Boitempo, 2008. ISBN 978-85-7559-068-3.

\section{OLIVEIRA, A. S. A situação do emprego formal em Uberlândia no período}

2010-2016. Uberlândia, 2018. CEPES/IERI/UFU. Disponível em: http://www.ie.ufu.br/sites/ie.ufu.br/files/Anexos/Bookpage/CEPES_PE_Situaca O_Emprego_Formal_em_Udia_\%202010_2016.pdf. Acesso em: 12 mar. 2019. 
SAVIANI, D. Transformações do capitalismo, do mundo do trabalho e da educação. In: LOMBARDI, J. C.; SAVIANI, D.; SANFELICE, J. L. Capitalismo, trabalho e Educação. $3^{a}$ Ed. Campinas. Autores Associados, 2005.

SAVIANI, D. Pedagogia Histórico-Crítica: primeiras aproximações. $10^{a}$ ed. Campinas: Autores Associados, 2008. ISBN 978-85-85701-09-3.

SAVIANI, D. PDE - Plano de Desenvolvimento da Educação: análise crítica da política do Mec. Campinas: Autores Associados, 2009. ISBN 978-85-7496-237-5.

SOARES, S A. G. Políticas Públicas, qualificação profissional e a educação do trabalhador no final da década de $\mathbf{9 0}$ no Brasil: empregabilidade ou inserção social? Tese de doutorado. Campinas: Unicamp, 1998. Disponível em:

http://repositorio.unicamp.br/jspui/handle/REPOSIP/251109. Acesso em: 27 ago. 2019.

TANO, C. F. S. Trabalho, educação e consenso: apoio do Estado ao setor produtivo x geração de empregos e empregabilidade. 2019.187 f. Tese (Doutorado em Educação) - Universidade Federal de Uberlândia,

Uberlândia, 2019. Disponível em: http://doi.org/10.14393/ufu.te.2019.2466. Acesso em: 27 ago. 2019.

TANO, C. F. S. Trabalho na agroindústria rural e política de expansão do ensino profissionalizante e tecnológico: a empregabilidade na microrregião de Ituiutaba de 2008 a 2015. Dissertação. Uberlândia. UFU, 2016. Disponível em: https://repositorio.ufu.br/handle/123456789/18109. Acesso em: 14 mar. 2018.

Recebido em: 11 de setembro de 2020 Aprovado em: 10 de dezembro de 2020 Publicado em: 28 de dezembro de 2020 